\title{
Reumatismo palindrómico (Enfermedad de Hench Rosemberg). Caso clínico con respuesta a los glucocorticoides
}

\author{
BÁRBARA C. FINN ${ }^{1}$, PABLO YOUNG ${ }^{1}$, HUGO LABORDE ${ }^{2}$, \\ GEOFREDO EARSMAN ${ }^{2}$, DAMIÁN DUARTES NOE ${ }^{2}$, \\ JUAN C. BARREIRA ${ }^{2}$, JULIO E. BRUETMAN ${ }^{1}$
}

'Servicio de Clínica Médica. ${ }^{2}$ Servicio de Reumatología. Hospital Británico, Buenos Aires, Argentina.

Recibido el 5 de octubre de 2009, aceptado el 1 de julio de 2010.

Correspondencia a: Dr. Pablo Young. Hospital Británico. Perdriel 74 (1280)

Buenos Aires, Argentina. Tel: 541143096400

Fax: 541143043393 E-mail: pabloyoung2003@ yahoo.com.ar

\section{Palindromic rheumatism. Report of one case}

Palindromic rheumatism is characterized by multiple recurrent episodes of arthritis and periarthritis (mono or oligoarticular) that may last hours or days, disappearing without sequels. We report a 69-year-old male with a history of hypertension and a presumptive diagnosis of gout due to recurrent episodes of arthritis and periarthritis in the last thirty years. They involved at least two joints, lasted few days and were self limited. The patient was admitted due to arthritis and periarthritis of both wrists, knees, ankles, elbows and hands. He presented with fever (38-39 $\mathrm{C})$, intense articular pain and anorexia. With a presumptive diagnosis of palindromic rheumatism and the lack of response to non steroidal anti inflammatory drugs, methylprednisolone $20 \mathrm{mg} / \mathrm{od}$ per os was started, with an excellent response.

(Rev Med Chile 2010; 138: 852-855).

Key words: Arthritis; Methylprednisolone; Periarthritis.
L as enfermedades articulares inflamatorias de curso episódico recurrente son una causa habitual de consulta, como sucede con las artritis por cristales y las artritis reactivas y mucho menos frecuente los síndromes periódicos, como la fiebre mediterránea familiar o las artropatías idiopáticas intermitentes, entre las que se cuenta el reumatismo palindrómico.

El reumatismo palindrómico $(\mathrm{RP})$ es una rara entidad caracterizada por episodios recurrentes de mono u oligoartritis, asociados a periartritis, sin fiebre, de curso autolimitado, que no deja secuelas y responde rápidamente con anti-inflamatorios no esteroidales (AINEs). Es bien conocido que un subgrupo de estos pacientes presenta un cuadro severo caracterizado por afección poliarticular, fiebre, curso prolongado y resistencia al tratamiento, como el caso de nuestro paciente.

Es nuestro objetivo comunicar un paciente que luego de excluir otras entidades se llegó al diagnós- tico de RP refractario al tratamiento, realizando una revisión de la literatura.

\section{Caso clínico}

Paciente de 69 años, sexo masculino con antecedentes de hipertensión arterial y episodios recurrentes de oligo o monoartritis de 30 años de evolución, autolimitados, interpretados como crisis gotosas sin análisis de líquido articular en dichos episodios, cuya localización era ambas muñecas, interfalángicas, codos, rodillas, tobillos, recibiendo AINEs y metilprednisolona en dosis de 4 miligramos durante las crisis. Los períodos intercríticos eran asintomáticos. Se hospitalizó por síndrome febril de $38-39^{\circ} \mathrm{C}$ axilar, asociado a la aparición de placas eritematosas, dolorosas, migratorias primero y luego aditivas de localización próxima a las articulaciones comprometidas; muñecas, codos, rodillas, tobillos, metacarpofa- 
lángicas e interfalángicas proximales de la mano izquierda. Posteriormente evolucionó como una poliartritis migratoria, hiporexia y deterioro del estado general. No presentó tofos.

El laboratorio evidenció hematocrito 37\%, glóbulos blancos $20.000 \mathrm{~mm}^{3}$ (fórmula conservada), VSG $>120 \mathrm{~mm} / \mathrm{h}$, proteína C reactiva $44 \mathrm{mg} / \mathrm{dl}$ (0,1-0,5 mg/dl), ácido úrico: $6 \mathrm{mg} / \mathrm{dl}$, colesterol total: $196 \mathrm{mg} / \mathrm{dl}$, factor antinuclear, Látex, anticuerpos anti-citrulina, ANCA $\mathrm{P}$ y C, crioglobulinas fueron negativos. HLA B27 negativo. Los anticuerpos anti parvovirus B19, VIH, serologías de hepatitis C, hepatitis B, clamidias, virus de Epstein Barr y citomegalovirus fueron negativos.

El examen del líquido articular mostró recuento celular a predominio mononuclear de $2.800 / \mathrm{mm}^{3}$, sin cristales y sin gérmenes y 4 pares de hemocultivos y 2 urocultivos fueron negativos. El examen radiológico de tórax, y de las regiones comprometidas (pies, manos y rodillas) no evidenció lesiones, calcificaciones intraarticulares o condrocalcinocis. Radiografías de sacroiliacas normales.

Con la sospecha diagnóstica de RP se inició tratamiento con indometacina $150 \mathrm{mg} /$ día por vía oral con una protección gástrica adecuada y control sistemático de la presión arterial ya que en este contexto clínico los AINEs están contraindicados, y ante la progresión de los síntomas con impotencia funcional luego de 72 hs se decidió iniciar tratamiento con metilprednisona $20 \mathrm{mg} /$ día por vía oral, obteniendo una dramática respuesta y remisión del cuadro clínico a las $48 \mathrm{~h}$. En su evolución, al mes, el paciente se encontraba asintomático y con reactantes de fase aguda en descenso, hasta normalizarlos; permaneció con dosis decrecientes de corticoides por un período de 3 meses manteniéndose asintomático luego de la suspensión hasta los 4 años de seguimiento.

\section{Discusión}

El término "palindrómico" deriva (del griego palin dromein, volver a ir hacia atrás) y es una palabra o frase que se lee igual hacia adelante que hacia atrás. La aplicación de este término a esta enfermedad reumatológica se debe a que son cuadros que "se van como vinieron".

La denominación de reumatismo palindrómico fue utilizada por primera vez por Hench y
Rosemberg ${ }^{1}$ en 1944, cuando describen la entidad como múltiples episodios recurrentes de artritis, periartritis, mono u oligoarticulares que duran desde unas horas a varios días, son episodios autolimitados que remiten sin dejar lesiones residuales. En 1959, Ansell y Bywaters ${ }^{2}$, en una serie de 28 pacientes plantean la estrecha relación entre esta entidad y la artritis reumatoidea (AR), afirmando que ambas serían variantes de la misma enfermedad con formas diferentes de presentación y evolución. Aproximadamente $50 \%$ de los pacientes con RP presentarán en algún momento de la evolución características clínicas, radiográficas y serológicas de AR. Es recién en el año 1987 que Hannonen y Pasero ${ }^{3,4}$ definen los criterios diagnósticos (Tabla 1). Nuestro paciente presentaba una enfermedad articular de larga evolución con episodios limitados sin secuelas clínicas y radiológicas, que alejaban el diagnóstico de gota o de otras sinovitis cristálicas y por otra parte, la forma de presentación como una poliartritis y extensa periartritis excedían a una AR, lupus eritematoso sistémico (LES) u otra enfermedad del tejido conectivo de compromiso poliarticular.

La forma de afectación articular más frecuente es de instalación súbita, con un máximo de intensidad en pocas horas, que aparece en cualquier momento del día $a^{5-15}$, compromete principalmente las rodillas, hombros, tobillos y codos, la mayoría de las crisis están limitadas a una o dos articulaciones pudiendo en casos severos comprometer más de cuatro como en nuestro caso. Es característico el gran compromiso de partes blandas que acompaña la afección generando intenso dolor ${ }^{3-5,15}$.

Si bien es habitual que la afección dure menos de 48 hs, se ha descripto un subgrupo de pacientes que presenta un curso más prolongado ${ }^{7,8,10}$, como el que observamos en nuestro paciente.

\section{Tabla 1 Criterios diagnósticos de reumatismo palindrómico ${ }^{3,4}$}

Historia de mínimo 6 meses de ataques súbitos, recurrentes de mono u oligoartritis con o sin afección de partes blandas

Observación de un ataque por el médico

Tres o más articulaciones afectadas en diferentes ataques

Ausencia de lesiones radiográficas

Exclusión de las otras formas de artritis 
Tabla 2. Diagnósticos diferenciales de reumatismos recurrentes ${ }^{10,15}$

Artritis cristálicas (gota, pirofosfato cálcico, hidroxiapatita)

Artritis reactivas

Artritis asociada a enfermedad inflamatoria intestinal

Enfermedad de Behçet

Hiperlipemia tipo II

Angioedema hereditario

Sinovitis eosinófilica

Hidrartrosis intermitente

Sarcoidosis

Fiebre mediterranea familiar

Enfermedad de Whipple

Policondritis recidivante

Se ha descrito la asociación del RP con osteartropatía hipertrófica primaria y síndrome antifosfolipídico ${ }^{15}$.

Dentro de los diagnósticos diferenciales de reumatismos episódicos se encuentran las sinovitis cristálicas y dentro de ellas, la gota es la única que presenta severo compromiso periarticular (Tabla 2). Nuestro paciente no había presentado podagra, ni elevación del ácido úrico durante las crisis o intercrítico, ni cristales en el líquido articular. El paciente nunca había presentado poliserositis y negaba la presencia de síntomas gastrointestinales. Nunca presentó ulceras orales o genitales recurrentes, ni alteración ocular con lo que se descartaría enfermedad de Behçet y las espondiloartrapatías.

Recientemente, González-López y col vuelven a plantear la relación entre el RP y la AR, describiendo en un análisis retrospectivo una cohorte de 113 pacientes, entre ellos había un subgrupo (30\% del total), que presentaban en su evolución gran compromiso periarticular, episodios más prolongados, y síntomas constitucionales (fiebre, VSG elevada, deterioro del estado general $)^{8-10}$; al igual que nuestro paciente. En este subgrupo era más frecuente la enfermedad en el sexo femenino, la afectación de las muñecas, rodillas y metacarpofalángicas, y la presencia de $\mathrm{FR}(+)^{7-10}$, evolucionando hacia otras enfermedades del tejido conectivo el $70 \%$ de los pacientes. Se ha descripto su evolución hacia AR, y de manera menos frecuente a LES, enfermedad de Behçet, espondiloartropatias, granulomatosis de Wegener, artritis psoriasica ${ }^{8-10,15}$. Recientemente el grupo de Hannonen y col, confirman los datos previos ya que $75 \%$ de sus 60 pacientes evolucionaron a AR luego de 20 años de seguimiento, la mayoría antes de los 10 años ${ }^{16}$.

Se ha demostrado que existen tres patrones de evolución de la enfermedad: 1) la remisión de los ataques, 2) curso clínico de ataques recurrentes sin afección persistente de la articulación, 3) evolución a enfermedad crónica, que en 25 a 50\% de los casos es una $\mathrm{AR}^{10,15}$. El período de latencia entre el comienzo del RP y el desarrollo de la AR es variable, varía entre pocas semanas a más de 10 años ${ }^{3}$.

Salvador y $\mathrm{col}^{17}$ destacan la presencia de anticuerpos anti-keratina y anti-citrulina en los pacientes con reumatismo palindrómico sugiriendo que esta entidad podría ser una forma abortiva de AR, no pudiendo establecer el valor predictivo de progresión a AR con estos anticuerpos. Russell y col describen una serie de 61 pacientes con RP, de los cuales 29 progresaron a AR luego de un seguimiento de 5,4 años; $83 \%$ de estos pacientes tuvieron anticuerpos anti-citrulina positivos, por lo que los autores concluyen que estos anticuerpos tienen mayor sensibilidad, especificidad y likelihood ratio que el FR para la predicción de $\mathrm{RP}$ a $\mathrm{AR}^{18}$. Recientemente Kim y col describen que existen diferentes patrones genéticos que condicionan la evolución y eventual transformación en $\mathrm{AR}^{19}$.

Diferentes modalidades terapéuticas han sido utilizadas tanto en las crisis como en las formas crónicas, se reconoce a los AINEs como el tratamiento de elección en el episodio agudo ${ }^{9-15}$. En los pacientes que no respondían, o los que formaban parte del subgrupo anteriormente descripto se han utilizado sales de oro ${ }^{3,10}$, D-penicilamina ${ }^{11}, y$ antimaláricos ${ }^{8,12}$ presentando respuestas clínicas muy variables. Algunos autores han planteado que en aquellos pacientes tratados con antimaláricos en forma prolongada se disminuiría la progresión hacia $\mathrm{AR}^{8-10}$. Por otra parte, el tratamiento con colchicina en forma preventiva en el período intercritico de la enfermedad no ha demostrado ser de utilidad ${ }^{14}$. La necesidad de recurrir a la utilización de corticoesteroides en pacientes que no responden con dosis adecuadas de AINEs, no ha sido comunicado previamente en pacientes con RP. Nuestro paciente con historia de recurrencia y episodios de corta duración en aproximadamente 30 años de evolución, presentó en esta oportuni- 
dad un rápido deterioro funcional y de su estado general con persistencia de la sintomatología que llevó a su internación, cuadro clínico que revirtió con esteroides sin recurrencia en su seguimiento a cuatro años. Creemos que aunque puede pensarse que la metilprednisolona $(20 \mathrm{mg})$ fue útil como antinflamatorio potente en el manejo de la crisis aguda, e inducir remisión, es muy osado atribuir la remisión por más de 4 años a este medicamento dado el curso impredecible del RP.

A pesar de las múltiples opciones descriptas en la literatura, no pudimos encontrar reportes sobre el tratamiento del episodio agudo con glucocorticoides, la excelente respuesta obtenida en nuestro paciente nos lleva a plantearlo como otra opción en las crisis.

Es de gran utilidad para el médico general que se enfrenta a afecciones articulares episódicas conocer la existencia del RP, su terapia y posibles evoluciones posteriores hacia otras artropatías.

\section{Referencias}

1. Hench PS, Rosemberg EF. Palindromic Rheumatism. A new recurring disease of joints (arthritis, periarthritis, para-arthritis) apparently producing no articular residues. Report of 34 cases; its relation to "angio-neural arthrosis", "allergic rheumatism" and rheumatoid arthritis. Arch Intern Med 1944; 73: 293-321.

2. Ansell BM, Bywaters EGL. Palindromic rheumatism. Ann Rheum Dis 1959; 18: 331-2.

3. Hannonen P, Möttönen T, Oka M. Palindromic rheumatism. A clinical survey of 60 patients. Scand J Rheumatol 1987; 16: 413-20.

4. Pasero G, Barbieri P. Palindromic rheumatism: you just have to think about it. Clin Exp Rheumatol 1986; 4: 1979.

5. Wajed MA, Brown DL, Currey HL. Palindronic rheumatism. Clinical and serum complement study. Ann Rheum Dis 1977; 36: 56-61.

6. Williams MH, Sheldon PJ, Torrigiani G, Eisen V, Mattingly S. Palindromic rheumatism. Clinical and inmunological studies. Ann Rheum Dis 1971; 30: 375-80.
7. Schumacher HR. Palindromic onset of rheumatoid arthritis. Clinical, synovial fluid and biopsy studies. Arthritis Rheum 1983; 25: 361-9.

8. González-López L, Gamez-Nava JI, Jhangri GS, RamosRemus C, Rusell AS, Suárez-Almanzor ME. Prognostic factors for the development of rheumatoid arthritis and other connective tissue diseases in patients with palindromic rheumatism. J Rheumatol 1999; 26: 540-5.

9. González-López L, Gamez-Nava JI, Jhangri G, Russell AS, Suárez-Almazor ME. Decreased progression to rheumatoid arthritis or other connective tissue diseases in patients with palindromic rheumatism treated with antimalarials. J Rheumatol 2000; 27: 41-6.

10. Guerne PA, Weisman MH. Palindromic rheumatism: part of or apart from spectrum of rheumatoid arthritis. Am J Med 1992; 93: 451-60.

11. Huskisson EC. Treatment of palindromic rheumatism with D-penicillamine. BMJ 1976; 2: 979.

12. Youssef W, Yan A, Russell AS. Palindromic rheumatism: a response to chloroquine. J Rheumatol 1991; 18: 35-7.

13. Golding DN. Sulphasalazine for palindromic rheumatism. Br J Rheumatol 1988; 27: 79. (Letter).

14. Schwartzberg M. Prophylactic colchicine therapy in palindromic rheumatism. J Rheumatol 1982; 9: 341-3. (Letter).

15. Sanmarti R, Cañete JD, Salvador G. Palindromic rheumatism and other relapsing arthritis. Best Pract Res Clin Rheumatol 2004; 18: 647-661. (Review).

16. Koskinen E, Hannonen P, Sokka T. Palindromic Rheumatism: Long term Outcomes of 60 Patients Diagnosed 1967-84. J Rheumatol 2009; 36: 1873-5.

17. Salvador G, Gómez A, Viñas O, Ercilla G, Cañete JD, Muñoz-Gómez J, et al. Prevalence and clinical significance of anti-cyclic citrullinated peptide and antikeratin antibodies in palindromic rheumatism. An abortive form of rheumatoid arthritis? Rheumatology 2003; 42: 972-75.

18. Russell AS, Devani A, Maksymowych WP. The role of anti-cyclic citrullinated peptide antibodies in predicting progression of palindromic rheumatism to rheumatoid arthritis. J Rheumatol 2006; 33: 1240-2.

19. Kim SK, Lee HS, Lee KW, Bae SC, Jun JB. Palindromic rheumatism: different genetic background implies a distinct disease entity. Ann Rheum Dis 2006; 65: 1539-40. 